\title{
A PRESERVAÇÃO DA INFÂNCIA: ANÁLISE DE DISCURSOS SOBRE A CRIANÇA EM PERIGO MORAL (PORTUGAL, 1910-1916)
}

\author{
Helder M. G. Henriques" \\ Instituto Politécnico de Portalegre (IPP-ESE) \\ Carla Cardoso Vilhena" \\ Universidade do Algarve (UAlg)
}

RESUMO: Neste trabalho procuramos analisar os discursos sobre a infância em perigo moral que circularam em Portugal nas primeiras décadas do século XX. Partindo do princípio de que um dos resultados da reconstrução da concepção de delinquência infantil, que ocorreu naquele período, é a emergência da categoria de crianças de risco, que se torna alvo privilegiado de um conjunto de ações profiláticas cuja principal finalidade é a prevenção da delinquência, procedemos à análise da legislação de proteção à infância e do periódico A Tutoria - Revista mensal defensora da infância, publicado entre 1912 e 1916. Esta análise teve como principais objetivos: compreender o processo de construção da criança em perigo moral, descrever a sua transformação numa questão pública e analisar as estratégias desenvolvidas no sentido de assegurar a sua normalidade.

Palavras-chave: Modernidade. Infância. Marginalidade. Criança em perigo moral.

\footnotetext{
http://dx.doi.org/10.1590/0102-4698132627

* Doutor em Ciências da Educação, com especialização em História da Educação, pela Universidade de Coimbra. Professor da Escola Superior de Educação do Instituto Politécnico de Portalegre (IPP/ESE). Investigador no CEIS20/Universidade de Coimbra. E-mail: henriqueshelder@gmail.com

** Professora Auxiliar na Faculdade de Ciências Humanas e Sociais da Universidade do Algarve. Investigadora no CEIS20/Universidade de Coimbra. E-mail: cvilhena@ualg.pt
} 


\title{
PRESERVING CHILDHOOD: A DISCOURSE ANALYSIS ABOUT CHILDREN AT MORAL RISK (PORTUGAL, 1910-1916)
}

\begin{abstract}
The purpose of this article is to explore the discourses about children at moral risk in Portugal in the early decades of the twentieth century. Reflecting changing attitudes to delinquency that began to emerge at the beginning of the twentieth century, children at risk became the subject and target of prophylactic interventions, designed with the aim of prevent delinquency and crime. Based on analysis of legislation concerned with child delinquency and protection, and of one magazine, A Tutoria - Revista mensal defensora da infância, published between 1912 and 1916, we examine how the notion of "child at moral risk" is constructed, describe its transformation on a public issue and analyze the strategies developed to ensure their normality.
\end{abstract}

Keywords: Modernity. Childhood. Marginality. Children at risk.

\section{INTRODUÇ̃̃o}

A percepção da infância como um período da vida fundamental para o futuro do homem e da sociedade, produto da modernidade, despertou o interesse por esta etapa da vida, que adquiriu, desde o século XVII, uma crescente importância do ponto de vista político, social e científico (HOFSTETTER, 2012; KING, 2007; SACRISTÁN, 2008). Uma das consequências do interesse pela infância, visível sobretudo a partir do século XIX, período em que emergiu a preocupação com a qualidade da população, foi o surgimento no debate público das questões relacionadas com a infância marginal que, iniciando-se pela emergência da criança delinquente, se expande para englobar todas as crianças consideradas em perigo moral (HENDRICK, 1999; TOMÉ, 2010).

O propósito deste trabalho prende-se com a problemática da infância em perigo moral e desamparada nas primeiras décadas do século XX, em Portugal. Assumimos que a infância só pode ser interpretada na sua relação variável com saberes e instituições que permitem a sua modelação e a sua compreensão. A nossa abordagem centrou-se essencialmente nas relações de poder estabelecidas com a infância na tentativa de evitar o seu processo de "anormalização". Para isso, tornou-se relevante compreender as políticas, as estratégias e as técnicas utilizadas para governar a infância, quer em perigo moral, quer desamparada, e moldá-la de acordo com os princípios discursivos normalizadores, definidos essencialmente pelo Estado.

A análise dos discursos acerca da intervenção preventiva realizada com as crianças em perigo moral, durante a $1^{\text {a }}$ República, 
em Portugal, constitui o principal objetivo deste trabalho. Assim, colocamos as seguintes questões de partida: Que características estavam associadas às crianças para serem consideradas seres em perigo social e moral? Como se posicionou o Estado sobre esse assunto? De que forma se poderia preservar a "pureza" da infância e evitar "desajustamentos" sociais e morais? Essas interrogações serviram de guias orientadores do nosso trabalho e foram pensadas a partir de um corpo teórico interdisciplinar, mas sobretudo ancorado à história da educação.

Esta é uma abordagem sócio-histórica, uma vez que permite dar ênfase aos processos, às variáveis, às relações entre a infância e aqueles que a tentam "normalizar". Assim, iniciamos este trabalho com as questões de partida identificadas anteriormente, procedendo em simultâneo à revisão do estado da arte e à análise documental, análise esta que permitiu identificar e descrever um conjunto de discursos sobre a infância em perigo moral que circularam em Portugal nos primeiros anos da $1^{\mathrm{a}}$ República.

O corpus documental utilizado foi constituído por duas partes complementares e interligadas: (1) a Lei de Proteção à Infância (LPI), promulgada em 1911; e (2) o periódico A Tutoria - Revista mensal defensora da infância (1912-1916).

Publicada em 27 de maio de 1911, a LPI é reflexo de uma visão moderna da criança e da delinquência infantil. Como afirma Tomé (2010), debateu-se um pouco por toda a Europa, na transição do século XIX para o século XX, a questão da proteção da infância, passando a criança a ser considerada assunto de Estado. Reconhecendo a especificidade da infância e assente numa visão da delinquência como um produto do meio, foi criado, através da LPI, um conjunto de estratégias de caráter preventivo e curativo que tinham como finalidade a proteção social de crianças e jovens, o seu resgate de meios nocivos ao seu desenvolvimento, como as famílias negligentes ou maltratantes e os tribunais e as prisões para adultos (AFONSO, 2011; TOMÉ, 2010).

Quatro meses após a promulgação da LPI, iniciou-se a publicação da revista $A$ Tutoria - Revista mensal defensora da infância. O seu principal objetivo seria tornar-se o espelho da ação da Federação Nacional dos Amigos e Defensores das Crianças, uma organização criada no âmbito da LPI e que consistia na "união jurídica, moral e facultativa de várias instituições, quer oficiais, quer particulares, de propaganda, educação e patronato, que deverão formar um verdadeiro sistema de higiene moral e social" (PORTUGAL, 1911b, p. 1.327), sendo-lhe 
atribuídas funções de caráter preventivo, tais como a educação das populações, e curativas, designadamente o auxílio ao tratamento dos menores sob a responsabilidade da Tutoria da Infância. Esse periódico deveria constituir-se, assim, num instrumento de propaganda, como é visível nas palavras de Sousa Costa (1912, p. 1), bacharel em Direito e um dos seus criadores, quando refere que a revista pretendia ser "o eco dessa instituição salutar - o eco dos seus benefícios e das suas aspirações, a fim de que cada um de vós, como indivíduo, e todos, como colectividade, como expressão concreta do Estado tutelar, possais avaliar a obra dos tribunais infantis em Portugal".

Por meio dessas palavras podemos inferir a importância que a análise dos discursos publicados em tal revista tem para a compreensão das concepções sobre a infância e da ação do Estado na "reconstrução" do lugar da infância em perigo moral ou em situação de delinquência, assim como das tecnologias de governação empregues na normalização da infância. É ainda de realçar que, como afirmam Ferreira e Mota (2013), essa publicação constitui um verdadeiro programa de modernidade, caraterístico da $1^{\text {a }}$ República, uma vez que:

é possível lerem-se as contradições entre autoridade e liberdade, assistência e controlo, a crescente racionalização das aprendizagens e dos quotidianos e vivências institucionais, por um lado, e a separação formação e proteção da criança face ao adulto, por outro, bem como as tensões geradas entre as preocupações de disciplina moral e mental com aqueloutra de emancipação. (FERREIRA; MOTA, 2013, p. 200)

Esse periódico é também reflexo de um programa de governo sobre uma determinada população, exposto na LPI de 1911, e fruto de um conjunto de racionalidades sobre a educação de crianças órfãs, desvalidas, delinquentes ou potencialmente ameaçadoras que surgem no debate público sobre estas questões e que serão apresentadas nos pontos que se seguem.

\section{MODERNIDADE, GOVERNO DA INFÂNCIA E MARGINALIDADE INFANTIL}

Com o advento da Modernidade assiste-se a uma transformação na forma como são dirigidas as populações, visível na emergência de novas formas de governar os indivíduos, assentes na modelação cognitiva de comportamentos (FOUCAULT, 2006a). Nesse contexto emergiram diferentes tecnologias de governação cujas principais finalidades eram, para além da manutenção da ordem social, a preservação e a melhoria da saúde física e psicológica das populações (FOUCAULT, 2007; ROSE, 1999). 
Foucault (2006b) refere-se a esta problemática fazendo menção à importância da relação emergente entre a ciência política, resultante da arte de governar, e a gestão da população, na sua singularidade. Para o filósofo francês "gerir a população não quer dizer gerir simplesmente a massa coletiva dos fenómenos ou geri-los simplesmente no nível de seus resultados globais"; pelo contrário, o governo do coletivo implica gerir a população "em profundidade, em fineza, e no detalhe” (FOUCAULT, 2006b, p. 302). O Estado assume assim, segundo Foucault (2006a), a população como seu principal alvo de ação, a partir de uma lógica triangular que articula soberania, disciplina e gestão governamental. O objetivo maior seria o de construir uma sociedade governável, de acordo com determinadas racionalidades produtoras de ordem social, a partir de cada um dos indivíduos que a compunha.

Concebida como uma etapa da vida em que se jogavam quer destinos individuais - o adulto em que cada criança se iria tornar -, quer coletivos - a sociedade futura -, a infância tornou-se, ao longo dos séculos XIX e XX, um dos períodos da vida mais intensamente governados (HENDRICK, 2007; ROSE, 1999). Saberes como a medicina, a psicologia e a pedagogia assumiram-se como ciências centrais neste processo que, em articulação com o Estado, possibilitou a construção de um novo "lugar" para a infância: a criança da Nação (HENDRICK, 1999). A infância assumiu, nesse contexto, outra centralidade na política dos Estados, tornando-se objeto de investimento e governação com vista ao progresso nacional (HENDRICK, 1999) e à melhoria da sociedade (HOFSTETTTER, 2012).

Uma das instituições disciplinares utilizadas na governação das populações e, mais concretamente, da infância, é a escola, que assume um lugar central na edificação dos discursos que colocam a criança como o futuro da nação. No interior da instituição escolar cruzam-se conhecimentos, normas e valores capazes de potenciar racionalidades modeladoras do indivíduo ou do seu comportamento em sociedade. Desse modo, a aposta do Estado na escola representou uma ação política instrumental de "governação dos escolares" capaz de consolidar os ideais de progresso associados à edificação de um Estado-Nação.

Para as crianças que, por motivos diversos, não se enquadravam no contexto escolar, designadamente aquelas cujo desenvolvimento "normal" se encontrava ameaçado, a institucionalização (CÂMARA, 2006; GONDRA, 2010; GONZALEZ, 2011), dirigida sobretudo às famílias das classes populares, alvo privilegiado da intervenção direta do Estado, transformou-se numa das várias formas possíveis da sua governação. Como afirma Câmara (2006, p. 318-319): 
Proposições direccionadas a interditar e regulamentar o trabalho infantil, a preceituar a escolarização obrigatória; a instituir a criação de tribunais especiais; a sugerir a inibição do poder paternal; a abordar o valor transcendente do meio social, familiar e educacional sobre a carga hereditária das crianças, bem como a formular as directrizes para uma nova organização das instituições destinadas a solucionar o problema da repressão e atendimento das crianças foram, gradativamente, concebidas objectivando comprometer o Estado em sua acção tutelar sobre a infância e o governo sobre as famílias de modo a compor uma relação directa entre criminalidade, abandono, delinquência e a situação moral, social e económica em que se encontravam as famílias pobres.

No caso da governação das crianças consideradas em risco, por estarem em perigo moral, como consta nos textos analisados, esta intervenção estava enquadrada num projeto político mais vasto, que tinha como principal finalidade a construção de uma nação civilizada (RIZZINI, 2004).

A infância, quer em perigo social, quer a perigosa - a criança delinquente -, representava um problema social que deveria ser resolvido por meio de um conjunto de ações capazes de modelar o indivíduo de acordo com determinados padrões sociais, de o civilizar. Assim, ao longo da modernidade, surgiram várias instituições, principalmente por iniciativa do Estado, cujo objetivo era responder a este problema específico. Tornara-se necessário conhecer essas crianças, as causas da sua condição e encontrar forma de "regenerálas" e devolvê-las à sociedade.

A partir de uma visão sobre a infância entendida como um período determinante para a vida futura, mas também como separado e distinto da adultícia, exigindo, por esse motivo, proteção por parte dos adultos, procurava-se, por meio da intervenção naquela faixa etária, atuar de uma forma preventiva. Embora esta intervenção fosse realizada em nome do bem-estar individual, era sobretudo o bem-estar social, a manutenção e a preservação de uma ordem social, que as elites sentiam ameaçada pela crescente degradação moral das crianças, sobretudo daquelas oriundas das classes populares, que surgiam como argumentos legitimadores da intervenção num domínio tradicionalmente privado, a família (CÂMARA, 2006; DONZELOT, 1986; MARTINS, 2010; SHANAHAN, 2007).

Foi nesse contexto que emergiram as primeiras sociedades protetoras da infância, com a finalidade, entre outras, de "aperfeiçoar os sistemas de educação, os métodos de higiene e a vigilância das crianças das classes pobres" (DONZELOT, 1986, p. 33), assim como um conjunto de estabelecimentos cuja principal função era moralizar estas crianças através do desenvolvimento de hábitos de trabalho e da inculcação de um conjunto de valores, tais como a honestidade, o bem comum ou a defesa da nação. 
Em Portugal, no período da $1^{\text {a }}$ República, assistiu-se à publicação de legislação que tinha como principal finalidade a assistência não só aos menores delinquentes, mas também às crianças abandonadas ou àquelas que, tendo família, se considerava encontrarem-se em perigo moral. Como afirma Fonte (2004, p. 2.003):

Partindo do pressuposto de que competiria ao governo central estudar e procurar atacar, com medidas preventivas, as causas ou actos que pudessem perturbar o bom funcionamento da sociedade, a acção governativa deveria começar por incidir sobre as crianças que estavam prestes a ser envolvidas na complexa engrenagem da luta pela vida e pela inserção social.

A primeira lei de proteção à infância publicada em Portugal data de 27 de maio de 1911 e teve como principal finalidade, como se pode ler no seu preâmbulo, "proteger, regenerar, tornar útil” (PORTUGAL, 1911b, p. 1.317) a criança "abandonada ou desprotegida", retirando-a de "ambientes viciados, que lhe envenenam a alma e o corpo" (PORTUGAL, 1911b, p. 1.317). A aplicação dos princípios veiculados na lei é garantida por dois organismos: a Tutoria da Infância, "tribunal colectivo especial, essencialmente de equidade, que se destina a defender e proteger as crianças em perigo moral, desamparadas ou delinquentes, sob a divisa: educação e trabalho" (PORTUGAL, 1911b, p. 1.317), e a Federaşão Nacional dos Amigos e Defensores das Crianças. Para além de cooperar com a Tutoria da Infância, no cumprimento dos acórdãos que daí emanavam, a Federação Nacional dos Amigos e Defensores das Criancas deveria atuar no sentido de "prevenir os males que podem produzir a degenerescência psíquica e moral das crianças" e, simultaneamente, agir junto com a sociedade, de forma a "fazer interessar todo o cidadão português pela conservação e desenvolvimento da saúde e moralidade dos seus filhos" (PORTUGAL, 1911b, p. 1.327).

A LPI tinha como alvo não só a criança perigosa, a delinquente, mas também a criança em perigo moral (abandonada, pobre, indigente), preconizando-se dois tipos de intervenção, que têm como denominador comum a crença no poder transformador da educação: uma intervenção preventiva, para as crianças em perigo; e uma reeducativa, para as crianças perigosas.

É, precisamente, a intervenção preventiva que tem como alvo a criança em perigo moral, que constitui o tema central deste texto. Nesse sentido, iremos proceder à análise da concepção de criança em perigo moral subjacente à LPI e veiculada no periódico $A$ Tutoria, para, em seguida, abordarmos as questões relativas à sua educação. 


\section{A CRIANCA EM PERIGO MORAL}

O processo de individualização da população contribuiu para que se desenvolvessem variadíssimos discursos sobre a infância "desajustada", sobre as causas deste(s) desajustamento(s), assim como sobre as suas consequências. Tanto na LPI como nos textos publicados na revista $A$ Tutoria, são identificadas e descritas diferentes categorias de crianças desajustadas - em perigo moral, desamparadas e delinquentes -, que possuíam em comum o fato de serem consideradas uma ameaça à ordem social presente e futura, um mal social que a sociedade, em nome da sua própria sobrevivência, deveria resolver. A LPI surge, precisamente, como solução para esse problema:

O intuito deste decreto é, pois, atender a um velho mal com indispensáveis medidas de saneamento sendo a primeira dessas medidas furtar a criança desprovida aos ambientes viciados, que lhe envenenam a alma e o corpo, aos meios de infecção intima, que depravam e inutilizam uma parte considerável da nossa população. (PORTUGAL, 1911b, p. 1. 316)

Os discursos sobre as crianças "desajustadas" possuíam também como elemento comum o facto de ao seu desajustamento serem atribuídas causas hereditárias, mas também fatores ambientais, sendo visível nos discursos analisados uma visão romântica da infância combinada com princípios evangélicos; mais concretamente, a criança é apresentada como um ser inocente, corrompido sobretudo por ação do meio, a quem era necessário proteger e disciplinar. Essa ideia é explicitada no preâmbulo da LPI, em que se defende que aos menores deve ser aplicado um regime legal diferente daquele que era aplicado aos adultos:

\footnotetext{
Produtos inconscientes do meio, da hereditariedade - aquele e esta actuando livres dos ditames disciplinadores da razão amadurecida - o seu julgamento deve ser mais ditado pelo espírito ponderado do julgador do que pela letra inflexível dos códigos. E nesses julgamentos, sôbre o critério do castigo, tem de prevalecer o critério da necessidade de despertar a criança para o cumprimento do bem, lavando-lhe a alma das sujidades, dos detritos em que nasceu e se desenvolveu, e mostrando-lhe a luz clara da verdade, os ensinamentos reabilitadores da justiça. (PORTUGAL, 1911b, p. 1.318)
}

Desse modo, a proteção e a disciplinarização da criança assumem um papel central na produção de bons cidadãos, uma vez que se entendia que a forma como era vivida a infância determinava aquilo que cada um se tornaria na idade adulta - "Da criança sai o homem, como da aurora o dia pleno" (PORTUGAL, 1911b, p. 1.317). Esse entendimento da criança como pai do homem reforça a importância 
da intervenção nessas idades, em nome do bem-estar individual, mas sobretudo do coletivo, sendo patente nos discursos analisados uma concepção da criança como Criança da Nação (HENDRICK, 1999). Essa concepção é visível, por exemplo, no preâmbulo da LPI, designadamente nos cálculos que se fazem das perdas que resultam, para o país, da não intervenção nessas idades: "Calculem-se os milhares de unidades que se perdem num país em que a assistência, a protecção à infância não passou, até esta data, das aspirações melancólicas dos legisladores do futuro!" (PORTUGAL, 1911b, p. 1.316).

É nesse contexto que é criada a Tutoria da Infância, um tribunal moderno, assente numa nova concepção de infância marginalizada, cuja principal função seria proceder à sua (re)educação e reabilitação, afastando-a do convívio com os adultos responsáveis pelo seu desajustamento social, como é visível nas palavras que António Macieira escreve no primeiro número da revista $A$ Tutoria:

\footnotetext{
Instituição moderna, estabelecida sob as bases do melhor que então existia nos diferentes estados que se interessam pela criminalidade infantil, a Tutoria afasta o menor criminoso, ou simplesmente abandonado ou maltratado, da atmosfera geral dos tribunais comuns, garantiu a esses infelizes modos especiais de tratamento que lhe asseguram no limite do possível a sua reabilitação e regeneração. (MACIEIRA, 1912, p. 3)
}

A intervenção exigia, contudo, que se definisse, em primeiro lugar, o que era uma criança em perigo moral, ou seja, quais as condições que permitiriam que uma determinada criança fosse colocada nessa categoria, tarefa realizada pelo legislador quando da formulação da LPI. Nesta lei são definidos três grupos de crianças em perigo moral: os menores abandonados, os pobres e os maltratados, sendo cada um deles objeto de determinações específicas.

Os menores em perigo moral seriam aqueles que não possuíam domicílio certo ou meios de subsistência; aqueles cujos pais ou tutores, devido a doença, prisão ou incapacidade, não cumprissem com os seus deveres; os menores cuja educação fosse deixada ao abandono e cujos pais ou tutores tivessem mau comportamento "notório e escandaloso" ou fossem mendigos, vadios, alcoólicos, gatunos, rufiões. Também aqueles menores que fossem objeto de maus-tratos físicos habituais ou excessivos, privados de alimentação ou de cuidados de saúde, empregados em profissões proibidas, perigosas ou desumanas ou que fossem "excitados para a gatunice, mendicidade ou prostituição" eram passíveis de ser classificados como estando em perigo moral. 
A integração das crianças pobres, apenas pela sua condição econômica, na categoria em perigo moral deve-se ao fato de a pobreza ser considerada, por si só, um fator potenciador de desvio moral e social, estabelecendo-se uma relação entre esta e a ausência de educação. As famílias pobres são descritas, quer na LPI, quer por aqueles que escrevem no periódico $A$ Tutoria, como incapazes de educar convenientemente os seus filhos, sendo esta classificação legitimada apenas pela referência à sua condição econômica. Como escreve Sousa Costa (1912), ao definir o que pretende ser a Tutoria da Infância, no primeiro número da revista:

É, evidentemente, o exercício de determinada tutela - exercício que no nosso caso recai sobre as crianças abandonadas, hastes sem raiz que o turbilhão da vida arrasta e perde, e sobre as crianças pobres, que precisam de tutela porque, num regime de miséria, vivendo embora com os pais, com a família, se encontram perigosamente desprovidas de todos os cuidados de corpo e de espírito que fundamentam a lógica e a necessidade de um corpo tutelar. (COSTA, 1912, p. 1)

A intervenção junto com essas crianças, as abandonadas, pobres e maltratadas, ou seja, aquelas que se considerava estarem em perigo moral, era realizada em nome não só do seu bem-estar, mas sobretudo em nome da manutenção da ordem social e da melhoria da qualidade das populações, havendo subjacentes preocupações de caráter eugênico, designadamente com a degenerescência da raça (FONSECA, 1913). A discussão pública desses temas e a sua ligação com a construção de um Estado moderno, civilizado, é visível na transcrição que José de Magalhães (1912, p. 19) faz de um artigo publicado no jornal A Lucta, em 12 de dezembro de 1910:

É sobre a preservação da infância e da adolescência contra a mortalidade, a morbilidade e a criminalidade, que deverá dirigir-se a solicitude do Estado republicano. É esta uma obra de interesse vital porque se prende com a necessidade de defesa nacional, do progresso económico e da saúde social.

A preservação da infância surge como investimento social para o futuro, caminho do progresso, e construção de uma sociedade regulada e ordenada, depositando-se na criança a esperança e a "responsabilidade" desse futuro. Nesse sentido, seria necessário garantir o seu normal desenvolvimento, desencadeando uma ação preventiva, assente na educação, dirigida àquelas crianças com as quais se considerava que o desvio à norma tinha uma maior probabilidade de ocorrer. É precisamente sobre essa ação profilática que nos iremos debruçar no ponto que se segue. 


\section{A PROFILAXIA DA MARGINALIDADE: OU 0 “DISCURSO DO ESTADO”}

A modernidade implica "razão de estado", consubstanciada em territórios técnico-institucionais específicos, apoiada em estratégias, técnicas e julgamentos dirigidos à população que tendem a potenciar uma determinada padronização social. Não obstante, esse processo de normalização social decorrente da presença de uma microfísica do poder permite evidenciar segmentos da população não alinhados com a racionalidade normalizadora proposta. Assim, o Estado, socorrendo-se de um conjunto de saberes em emergência (psicologia, medicina, direito), tenta encontrar resposta para os problemas sociais decorrentes do processo regulador, designadamente para a construção de um "Homem Novo", um cidadão disciplinado e conforme à norma social. Como afirmam Popkewitz e Bloch (2000, p. 35):

\footnotetext{
Numerosos intelectuais, grandes homens de negócios e líderes religiosos e políticos acreditavam que o progresso social estava associado ao desenvolvimento de um 'Homem Novo'. Este termo, muito em voga nos EUA e na Europa, implica o desenvolvimento de uma disciplina interior que permitiria aos indivíduos controlar a sua existência mundana.
}

Uma das questões para as quais se procurou encontrar uma solução, ao longo dos séculos XIX e XX, uma vez que se considerava constituir uma ameaça à construção do Homem Novo, foi o problema da marginalidade na infância, que alcançava nesse período uma maior visibilidade social e política, para a qual teria contribuído a transformação dos problemas da infância numa questão social (FERREIRA, 2000). Mais concretamente, a emergência de uma nova sensibilidade relativamente a essa faixa etária conduziu à exposição pública dos problemas que afetavam as crianças, tais como a mendicidade, a vadiagem ou a falta de educação, entendidos não mais como problemas individuais, mas, sim, como uma ameaça geracional que colocava em risco o projeto de construção de uma sociedade moderna e civilizada.

Os ideais desse novo projeto foram amplamente divulgados e defendidos pelo regime republicano português (1910-1926). A educação tornara-se o elemento central do processo de regeneração da sociedade portuguesa; como defende Pintassilgo $(2009$, p. 2), "é à educação que é atribuída a missão de construir o 'homem novo' republicano, o cidadão consciente e participativo capaz de garantir a permanência do novo regime". Essa mensagem republicana encontra a sua melhor expressão no preâmbulo do Decreto de 29 de março de 1911, no qual se pode ler: "o homem vale, sobretudo, pela educação que possui" (PORTUGAL, 
1911a, p. 1.341). Esta frase constituiu a sistematização do pensamento educativo republicano, que aponta para a regeneração e o progresso social por meio da educação, patente também na LPI, como é possível verificar pela leitura do excerto que se segue:

Só com crianças educadas num regime escolar disciplinado, com uma higiene moral escrupulosa, instruídas, no conhecimento das cousas e na prática das leis sentimentais que formam carateres, das leis sociais que formam actividades positivas, se poderá construir uma sociedade que à salubridade dos costumes reúna as ansiedades fecundas do saber e do trabalho. (PORTUGAL, 1911b, p. 1.316-1317)

É nesse contexto que surgem, não só em Portugal, mas por todo o mundo ocidental, como é dado conta na rúbrica Pelo estrangeiro da revista $A$ Tutoria, várias instituições com caráter preventivo, cujo público-alvo seria a criança em perigo moral, e/ou de caráter curativo, dirigidas à reeducação da criança delinquente. Nessas instituições, de que a Tutoria da Infância criada pela LPI é um exemplo, procurava-se mais a compreensão das causas dos problemas da infância do que propriamente a sanção, assim como a identificação de técnicas/processos educativos eficazes que permitissem o desenvolvimento normal da criança (DONZELOT, 1986; SILVA JÚNIOR; ANDRADE, 2007). Tratava-se, portanto, de uma tentativa de controlar os indivíduos que eram ou podiam tornarse potencialmente perigosos para a sociedade, mas também de tentar perceber as causas e as motivações para a sua "fuga" à normalidade. Como explica Pedro de Castro (1912, p. 36):

A nossa obrigação é estudar os males de que enfermam os menores entregues à nossa guarda, paralelamente indicar o remédio que deverá aplicar-se para se conseguir a cura, e também para se evitar a propagação da doença.

Só por esta forma é que, a nosso ver, se poderá executar proveitosamente a obra de saneamento moral a que foi destinado o decreto de 27 de maio de 1911.

A família, por um lado, e as instituições de preservação ou reeducação de crianças, por outro, podem, assim, ser entendidas como duas partes do mesmo todo. As tentativas de resolução dos problemas da infância, com o objetivo de construir indivíduos úteis, produtivos e dóceis, cidadãos conformes às normas sociais (FOUCAULT, 2006b), tinham como alvo principal a família, locus de desenvolvimento da criança, que, quando incapaz de desempenhar eficazmente a sua função, seria substituída pelo Estado. Este exercia a sua ação por meio de instituições que tinham como principal alvo as crianças privadas de um meio familiar normal, ou seja, como é descrito no preâmbulo da LPI, aquelas que 
abandonadas a si mesmas, sem família, sem parentes, ou com família e parentes que se resvalam no vício e na perversão; entregues a pais ou tutores que, pela sua pobreza, não podem educá-las, ou que as transformam em pequeninos mártires inocentes da ferocidade de instintos irrefreáveis, maltratando-as, estabelecendo injustas e perigosas diferenças entre elas e os irmãos, obrigando-as a esmolar, a vadiar, não são ainda o crime, mas preparam-se, no ambiente próprio, para o ser, na melhor das oportunidades. Daí a obrigação do Estado, ou de qualquer entidade particular, autorizada, e constituída com o mesmo fim, de as arrancar a esse ambiente corruptor e de as tutelar enquanto não estiverem aptas a declararem-se emancipadas pelo trabalho e pelas responsabilidades. (PORTUGAL, 1911b, p. 1.317)

A proteção e a reeducação das crianças transformaram-se em causas públicas, e a ação preventiva face à marginalidade constituiuse como um dos caminhos a seguir. Ao longo da análise que realizámos, evidenciaram-se duas dimensões na retórica discursiva daquele tempo sobre esse assunto: o aprofundamento do interesse do Estado em relação a esse segmento da população; e a valorização da educação como elemento preventivo da marginalidade, capaz de produzir sujeitos normais e evitar problemas futuros. A proteção à infância assumiu-se como um desígnio do Estado, uma responsabilidade a que este, em nome da saúde do organismo social, mas também da modernização do país, não se pode furtar, como é visível nas palavras de Sousa Costa (1912, p. 1):

é ao Estado o principal interessado em tornar oxigenado e sadio o ar que respiramos, o ambiente em que hão de desenvolver-se e fructificar as nossas actividades, constitutivas da sua própria actividade, que incumbe prover à falta de pais, dos tutores ou à sua documentada incompetência.

O Estado constituía-se, assim, em parens patriae, em pai de família, substituindo-se a esta nos casos em que a sua ação era considerada socialmente prejudicial (POPKEWITZ; BLOCH, 2000), ou seja, quando se considerava que o ambiente familiar se poderia constituir como elemento potenciador de práticas e comportamentos comprometedores da ordem social instituída.

A intervenção do Estado na profilaxia da marginalidade tornou-se mais evidente, em Portugal, com a publicação da Lei de Proteção à Infância, de 1911, que criou a Tutoria da Infância. A criação desse "tribunal" é o exemplo mais claro do papel que o governo foi assumindo ao longo da centúria de 1900 no que diz respeito à problemática presente neste texto. O objetivo principal do órgão era "defender e proteger os menores em perigo moral, desamparados ou delinquentes" (PORTUGAL, 1911b, p. 1.318), promovendo, se fosse caso disso, a institucionalização de crianças e jovens para evitar problemas maiores à sociedade, quer presente, quer futura. 
A inibição do poder paternal, associada à pobreza e ao superior interesse da visão do Estado sobre a criança, podia assumir as seguintes formas: sob a guarda, defesa e proteção da República, abrangendo o conjunto dos direitos dos pais ou tutores sobre os menores; sob a guarda e defesa da República, correspondendo a inibição do poder paternal apenas aos filhos menores de 16 anos; sob a guarda da República, inibindo parte do poder paternal, nomeadamente "o exercício dos direitos de guarda, educação, correcção, administração do pecúlio e consentimento para alistamento no exército" (PORTUGAL, 1911b, p. 1.320) devido a maus-tratos e desprezo dos pais em relação aos filhos; sob a defesa da República, inibindo os poderes do pai, passando estes poderes a serem exercidos pela mãe se tiver condições para assegurar a educação dos filhos e prover a sua guarda; e, por fim, sob a proteção da República, inibindo os poderes do pai, da mãe ou do tutor relativamente à guarda, à educação e à correção de todos ou de parte dos filhos menores de 12 anos devido a incapacidades de cumprir os deveres paternos.

Em qualquer uma das situações assinaladas, o Estado substituía-se ao poder paternal, colocando os menores em instituições ou famílias adoptivas e governando a sua conduta de modo a transformá-los em sujeitos socialmente úteis e, consequentemente, normalizados e controlados. A preservação da infância em perigo moral, nessa altura, passava, assim, pelo afastamento das crianças de meios viciados que frequentavam devido à incapacidade dos pais ou tutores, por diferentes motivos, para lidar com os seus dependentes.

Independentemente dos fatores que estavam na origem do "desajustamento", todos os menores abrangidos pela LPI tinham em comum o fato de necessitarem, na opinião do legislador, de ser acompanhados, vigiados. Defensores de uma lógica preventiva, os autores que escreviam na Tutoria defendiam que esta vigilância se devia iniciar desde muito cedo, mais concretamente, desde o momento da concepção, tendo como público-alvo a mulher e como objetivo a prevenção de problemas que, mais tarde, pudessem estar associados ao desenvolvimento biopsicossocial, físico e moral das crianças. A esse propósito, Alexandre Barbas (1913b, p. 88) defendia:

Não deve a maternidade ser apenas uma enfermaria de parturientes na qual se recolha a mulher no último período da gravidez, para depois se deixar sem conforto no meio da miséria, entregue ao seus desespero e às vaias vergonhosas dum público desnaturado. A sua acção tem de ser mais franca, e para ser mais eficaz, deve ter delegadas de vigilância junto das fábricas, em toda a parte onde trabalhe a mulher, para que possa, quando se reconhecer mãe, receber os respetivos auxílios da «Maternidade» na certeza absoluta de que o pequeno ser que lhe palpita no ventre, terá um berço limpo [...] Evitar-se-iam assim muitos crimes que dia a dia estão alarmando os grandes centros. 
O autor realça o papel que os especialistas deviam ter no acompanhamento das mulheres, sobretudo aquelas que viviam em piores condições morais e materiais, constituindo esta vigilância uma forma de garantir a ordem social e evitar problemas de criminalidade infantil/juvenil no futuro. Nessa linha discursiva, encontramos outros autores, como José Magalhães (1912), que defendiam que o papel do Estado na assistência pública, designadamente na proteção à infância, devia abranger diferentes períodos dessa fase da vida, iniciando-se pela proteção da mãe durante o período da gravidez e continuando, após o nascimento, na proteção à criança.

Para que esta protecção seja eficaz, deve ela abranger a vida inteira da criança desde a gestação - poder-se-ia mesmo dizer -, desde o momento da concepção até ao findar da adolescência. Nesta ordem de ideias, passava em revista: a protecção da mãe durante o período da gravidez, durante o parto; depois do parto; a proteção do recém-nascido e da primeira infância; a protecção das crianças fracas ou doentes; crianças materialmente ou moralmente abandonadas e os anormais. (MAGALHÃES, 1912, p. 20)

Entendia-se que constituía responsabilidade do Estado zelar pela proteção do ser humano nas suas primeiras etapas da vida, protegendo especialmente aqueles que, pelas suas condições de vida, se encontravam mais vulneráveis, mais passíveis de ter um percurso de desenvolvimento "anormal".

A ênfase colocada no papel do meio na formação da personalidade - "são os homens de letras, artistas, os próprios governos a arejar, a humanizar a legislação, tratando da criminalidade infantil, como consequência lógica, fatal do meio e não como consequência do livre-arbítrio teológico" (A JUSTIÇA, 1912, p. 11) -, acompanhada por uma nova concepção da criminalidade infantil, teve como consequência a emergência de uma nova abordagem à questão da prevenção do desvio. Nesse sentido os autores que escrevem no periódico $A$ Tutoria defendiam que um dos elementos essenciais da profilaxia do desajustamento era, precisamente, impedir que as crianças contatassem com meios considerados nocivos ao seu desenvolvimento, numa idade em que se considera estarem especialmente predispostas à sugestão. Como afirma Alexandre Barbas (1912a, p. 6), num artigo intitulado "Acção moral da Tutoria":

A sua missão não é fazer do criminoso um santo, mas evitar que as crianças, em que dominam ainda as primeiras paixões, em que os instintos escravizam a razão, se convertam em criminosos, se assim se pode chamar aos indivíduos que, abandonados ao acaso, às aventuras do tempo, se anormalizaram. 
Embora essencial para evitar a "anormalização" dos menores, o afastamento dos menores de um meio ambiente nocivo ao seu desenvolvimento não garantia, por si só, o sucesso. Tal só seria alcançado se a par com a subtração da criança a influências nefastas se iniciasse um processo educativo, capaz de a colocar no caminho do bem, através do desenvolvimento de um conjunto de atitudes e valores consentâneos com a moral oficial, tais como a solidariedade e o amor ao trabalho, garantia de construção de seres disciplinados e produtivos que contribuíssem para a prosperidade e o desenvolvimento da nação: "Não basta salvar as crianças da rua e da cadeia. É necessário fazer delas "valores sociais"' (A TUTORIA, 1913, p. 13). Nesse contexto, a educação emerge como uma arma poderosa para transformar as crianças em cidadãos úteis e socialmente produtivos, nomeadamente aquelas que se encontravam em perigo moral.

\section{MAIS VALE EDUCAR DO QUE REMEDIAR!}

O estabelecimento de uma ligação, potenciada pelos discursos produzidos pelos reformadores, entre os problemas sociais e a educação das famílias e das crianças (POPKEWITZ; BLOCH, 2000) transforma a educação numa das armas mais poderosas de combate aos problemas que afetam a infância, como elemento central no processo de prevenção de ações e comportamentos desviantes, na manutenção da ordem social.

Tal como é postulado na LPI, caberia ao Estado a articulação entre a tutela das crianças em perigo moral e uma educação apropriada, quer no seio de famílias adotivas, quer em estabelecimentos criados para o efeito, os estabelecimentos de educação preventiva, elemento essencial para a profilaxia da marginalidade, entendida como "sobretudo um problema educativo", segundo afirma Mendes Correia (1913a, p. 181). Este autor reforça essa ideia quando escreve: "Muitos criminosos de hábito praticaram muito cedo os seus primeiros actos criminosos, mas não teriam resvalado na delinquência habitual se uma educação cuidada lhes houvesse a tempo atalhado as tendências" (CORREIA, 1913a, p. 181).

A educação das crianças transforma-se na principal arma de combate ao desvio social, a estratégia a se utilizar na construção de uma "vontade esclarecida, forte e autónoma", um caminho que Portugal tem de percorrer "no seio da família, na escola, em todo o meio social" (CORREIA, 1913b, p. 195). Educação e assistência combinam-se, assim, de forma a garantir a construção de uma sociedade moderna, 
civilizada. Um mundo bárbaro, em que não há qualquer preocupação com a infância (CALDAS, 1913, p. 54), é substituído por uma realidade em que a esta se torna o elemento central do processo de regeneração social, que se alcança, como explica Alexandre Barbas (1912b, p. 21), por meio da educação:

\begin{abstract}
A sociedade não se muda, não se transforma pelas leis, nem a detonações de espingardas. Só se muda a sociedade, quando se transformar o homem e este apenas se transformará pela educação, seguida das modificações económicas.

Não vem agora a proposito alargar-me em considerações pedagógicas acerca dos processos de educação que, segundo Eduardo Roehrich, é a arte de criar e estabelecer relações naturais e artificiais entre uma determinada individualidade e o mundo exterior, de maneira a dirigir o seu pensamento e a sua vontade para a perfeição moral. O fim, porém, de todos eles, é criar no educando novas necessidades de ordem intelectual, estética e moral, e desvendar-lhe os meios mais adequados para as satisfazer. Mas, se falta na infância, quando a animalidade impera com todas as suas exigências, quando despertam com toda a rudeza os instinctos, que se poderá esperar dessa criança?
\end{abstract}

A transformação das crianças em perigo moral em valores sociais é, assim, realizada em estabelecimento de educação preventiva, no seio dos quais se conjugam dois elementos considerados essenciais: educação e trabalho. A ênfase colocada nestas duas "dimensões pedagógicas" deve-se a considerar-se que estas têm um duplo caráter, regenerador e preventivo, contribuindo, assim, para a construção de cidadãos produtivos e disciplinados, como se pode observar pelas leituras das palavras escritas por Alexandre Barbas (1912a, p. 8):

Educação e trabalho, os maiores, e os mais irreconciliáveis inimigos do crime; educação que discipline a vontade e vigie os instintos, trabalho que preocupe o espírito levando-o a desenvolver e a concentrar a sua actividade. É a falta de educação na infância que origina o vício, como é a ociosidade que o alimenta e ramifica.

A uma vida de ócio e vagabundagem, origem de todos os vícios, opõe-se assim um quotidiano de normas e trabalho, disciplinado e disciplinador, em que a educação moral desempenha um papel essencial. A transmissão de valores, por meio do exemplo, das leituras, das atividades desenvolvidas, é uma preocupação dos autores que escrevem no periódico, designadamente a partir da solidariedade, peça fundamental na construção de uma sociedade harmoniosa e ordeira: "A lealdade e a dedicação, por exemplo, deviam cultivar-se entre os nossos internados, para amarem essa grande virtude que supõe o triunfo da justiça - a solidariedade" (BARBAS, 1913b, p. 54).

A possibilidade de evitar na infância "desajustamentos" e potenciar a inclusão social das crianças num espaço regulado e 
orientado por determinados padrões constituiu-se como motivo de ação do Estado em relação às crianças, às famílias, às políticas educativas e de regeneração e à definição do seu próprio papel no que diz respeito à "defesa da sociedade".

\section{CONSIDERAC̣̃̃ES FINAIS}

A modernidade possibilitou a emergência da infância enquanto época da vida com um valor próprio e a ser salvaguarda em benefício da nação. A sua importância é revelada nos discursos dos reformadores sociais, na centralidade desse período da vida para diferentes especialistas, na relação com a estrutura familiar e no processo de "estatização da infância". Desde o século XVIII que o Estado Português assumiu o interesse na construção de uma sociedade ordenada, regulada e com princípios racionais em que a infância e as instituições primárias de socialização da criança assumiram destaque.

Esse "sentido de ordem" que o Estado imprimiu à sociedade, utilizando a infância e a juventude, possibilitou o "desocultamento" de outros tipos de infância: a órfã, a desvalida, a pobre ou a delinquente, ou seja, a infância classificada como marginal por não se enquadrar no padrão social e, por isso, representar um perigo social e moral para a sociedade. Tornou-se necessário agir junto desse universo desajustado, umas vezes prevenindo situações de risco, quando ainda era possível; outras vezes, tentando regenerar os indivíduos que já tinham agido contra a sociedade. Foi sobre a prevenção que nos debruçamos.

De acordo com a retórica discursiva da época, as crianças que se encontravam em perigo social provinham de famílias pobres, consideradas meios potenciadores de práticas e comportamentos desajustados. Ao Estado coube o papel de encontrar políticas adequadas que evitassem a "anormalização" do indivíduo. A sua ação preventiva pode ser verificada na Lei de Proteção à Infância, de 1911, em que a $1^{\text {a }}$ República portuguesa revela a sua preocupação com esta infância diferente. $\mathrm{Na}$ tentativa de construir um "Homem Novo", procurou-se edificar uma consciência coletiva da importância de todos no processo, e para isso era necessário aproveitar os esforços e os serviços do pedagogo, do médico, do industrial, do agricultor e do filantropo, o que permitiria identificar os problemas e solucioná-los de forma a evitar colocar o futuro da nação em causa.

A educação assumiu em todo esse processo um papel crucial. Caberia à escola, em articulação com o trabalho, a preservação do estado de pureza da infância. Era necessário promover uma educação 
apropriada ao desenvolvimento harmonioso da criança, que, no fundo, permitisse moldá-la e governar a sua conduta.

Mas esse processo tinha outra dimensão relevante: a educação e a vigilância da família. Quando os ambientes familiares não eram considerados apropriados, o Estado acionava o seu poder legal de assumir o controle sobre uma determinada criança. Assim, colocava-a em diferentes contextos técnico-institucionais, onde a criança era estudada, e a sua conduta, moldada a partir de conhecimentos científicos em cruzamento com princípios e valores considerados adequados.

\section{REFERÊNCIAS}

A JUSTIÇA feita pela bondade (1912, outubro). A Tutoria, Lisboa, Portugal, v. 1, n. 1, p. 11. A TUTORIA Central (1913, outubro). A Tutoria, Lisboa, Portugal, v. 2, n. 1, p. 13.

AFONSO, J. A. O nascimento de uma instituição educativa republicana. Argumentos científicos e pedagógicos. Revista da FLUP, História, Porto, v. 4, n. 1, p. 183-207, 2011.

BARBAS, A. Acção moral da Tutoria. A Tutoria, Lisboa, Portugal, v. 1, n. 1, p. 5-8, out. 1912 a. Educação popular. A Tutoria, Lisboa, Portugal, v. 1, n. 2, p. 21-23, nov. 1912b. Educação moral. A Tutoria, Lisboa, Portugal, v. 1, n. 4, p. 54, jan. 1913 a. Maternidade. A Tutoria, Lisboa, Portugal, v. 1, n. 6, p. 86-88, mar. 1913 b.

CALDAS, J. A Tutoria da Infância. A Tutoria, Lisboa, Portugal, v. I, n. 4, p. 54, jan. 1913. CÂMARA, S. Para uma ação preventiva e curativa da infância pobre. In: FERNANDES, R. et al. (Orgs.). Para a compreensão histórica da infância. Porto: Campo das Letras, 2006. p. 313-334. CASTRO, P. Causas da criminalidade infantil. A Tutoria, Lisboa, Portugal, v. 1, n. 3, p. 35-36, dez. 1912. CORREIA, M. A criminalidade precoce. A Tutoria, Lisboa, Portugal, v. 1, n. 11, p. 179-181, ago 1913 a. . A educação e a criminalidade. A Tutoria, Lisboa, Portugal, v. 2, n. 1, p. 194 -195, set. 1913 b.

COSTA, S. A quem nos lêr, A Tutoria, Lisboa, Portugal, v. 1, n. 1, p. 1, out. 1912.

DONZELOT, J. A polícia das famílias. Rio de Janeiro: Edições Graal, 1986.

FERREIRA, A. G.; MOTA, L. A produção da infância na imprensa de educação e ensino durante a Primeira República em Portugal: A Tutoria. Revista Mensal Defensora da Infância (1912-1916). In: DÍAZ, J. M. H. (Org.). Prensa pedagógica y patrimonio bistórico educativo. Salamanca: Ediciones Universidad de Salamanca, 2013. p. 197-208.

FERREIRA, M. M. Salvar os corpos, forjar a razão: Contributo para uma análise crítica da criança e da infância como construção social em Portugal. Lisboa: Instituto de Inovação Educacional, 2000.

FONSECA, J. A. F. da. Estudos médico-sociais: A luta contra a degenerescência. A Tutoria, Lisboa, Portugal, v. 1, n. 7, p. 101-104, abr. 1913.

FONTE, T. A. No limiar da honra e da pobreza: A infância desvalida e abandonada no Alto Minho (1698-1924). 2004. 528 f. Tese (Doutorado em História) - Instituto de Ciências Sociais, Universidade do Minho, Braga, 2004. Trabalho não publicado.

FOUCAULT, M. É preciso defender a sociedade. Lisboa: Livros do Brasil, 2006 a. 
Estratégia, Poder-Saber. Rio de Janeiro: Forense Universitária, 2006b.

Microfísica do poder. São Paulo: Edições Graal, 2007.

GONDRA, J. G. A emergência da infância. Educação em Revista, Belo Horizonte, v. 26, n. 1, p. 195-214, 2010.

GONZÁLEZ, M. C. Medicina y pedagogia: La construcción de la categoria "infancia anormal" en España (1900-1939). Madrid: Consejo Superior de Investigaciones Cientificas, 2011.

HENDRICK, H. Constructions and reconstructions of British childhood: An interpretative survey, 1800 to the present. In: JAMES, A.; PROUT, A. (Eds.). Constructing and reconstructing childhood: Contemporary issues in the sociological study of childhood. London: Falmer Press, 1999. p. 34-62.

Optimism and hope versus anxiety and narcissism: Some thoughts on children's welfare yesterday and today. History of Education, v. 36, n. 6, p. 747-768, 2007.

HOFSTETTER, R. La transformation de l'enfant en écolier (du $19^{\mathrm{e}}$ au milieu du $20^{\mathrm{e}}$ siècle): Les "eurêkas" des sciences de l'homme naissantes, entre scientisme et romantisme: Un "naturalisme" de l'enfance, Paedagogica Historica, v. 48, n. 1, p. 31-50, 2012.

KING, M. Concepts of childhood: What we know and where we might go. Renaissance Quarterly, Chicago, v. 60, n. 2, p. 371-407, 2007.

MACIEIRA, A. A obra da República. A Tutoria, Lisboa, Portugal, v. 1, n. 1, p. 2-3, out. 1912. MAGALHÃES, J. Preservação da infância. A Tutoria, Lisboa, Portugal, v. I, n. 2, p. 20, nov. 1912. MARTINS, E. C. A outra educação da infância sem voz expressa na literatura (Séc. XIX XX), EducareEducere, Castelo Branco, n. 14, p. 99-119, 2010. (número especial).

PINTASSILGO, J. A República e a educação: Do ideal às realizações. In: AFONSO, A.; SAMARA, M. A. (Orgs.). O Congresso republicano de Setúbal: O Republicanismo entre a Revolução e a Ordem. Setúbal: Instituto Politécnico de Setúbal, 2009. p. 25-37.

POPKEWITZ, T.; BLOCH, M. Construindo a criança e a família: Registos de administração social e registos de liberdade. In: NÓVOA, A.; SCHRIEWER, J. (Eds.). A difusão mundial da escola. Lisboa: Educa, 2000. p. 33-68.

PORTUGAL. Decreto com força de lei de 29 de março, reforma o ensino infantil, primário e normal. Diário do Governo $n^{\circ}$ 73. Ministério do Interior, Lisboa, 1911a.

PORTUGAL. Decreto com força de lei de 27 de maio, criando instituições de protecção às crianças e regulando a respectiva organização. Diário do Governo nº 137. Ministério da Justiça, Lisboa, 1911b.

RIZZINI, I. O cidadão polido e o selvagem: A educação dos meninos desvalidos na Amazónia Imperial. 430 f. Tese (Doutorado em História Social) - Instituto de Filosofia e Ciências Sociais, Universidade Federal do Rio de Janeiro, Rio de Janeiro. 2004. Trabalho não publicado. ROSE, N. Governing the soul: The shaping of the private self. London: Free Association Books, 1999. SANCRISTÁN, M. S. 'Los inicios de la protección a la infancia en España (1873- 1918). In: IX CONGRESO INTERNACIONAL DE LA ASOCIACIÓN ESPAÑOLA DE HISTORIA ECONÓMICA, 9., set. 2008, Murcia, Espanha. Atas... Múrcia: Universidad de Murcia, 2008. Disponível em: <http://www.um.es/ixcongresoaehe /pdf $/$ Los $\% 20$ inicios $\% 20$ de $\% 201$ a $\% 20$ proteccion $\% 20$ infancia.pdf $>$. Acesso em: 10 jan. 2013.

SHANAHAN, S. Lost and found: The sociological ambivalence toward childhood. Annual Review of Sociology, n. 33, p. 407-428, 2007. 
SILVA JÚNIOR, N. G. S.; ANDRADE, A. N. “É melhor pra você!": Normatização social da infância e da família no Brasil. Revista do Departamento de Psicologia-UFF, Niterói, v. 19, n. 2, p. 423-438, 2007.

TOMÉ, M. R. A cidadania infantil na Primeira República e a tutoria da infância. A criação da Tutoria de Coimbra e o refúgio anexo. Revista de História da Sociedade e da Cultura, Coimbra, v. II, n. 10, p. 481-500, 2010.

Recebido: $31 / 03 / 2014$

Aprovado: 07/01/2015

Contato:

Instituto Politécnico de Portalegre Escola Superior de Educação/CEISXX Lugar da Abadessa 7301- 901

Portalegre, Portugal

245300200 
